\title{
BMJ Open Prevalence of non-communicable disease risk factors among poor shantytown residents in Dhaka, Bangladesh: a community-based cross- sectional survey
}

Md Khalequzzaman, ${ }^{1}$ Chifa Chiang, ${ }^{2}$ Sohel Reza Choudhury, ${ }^{3}$ Hiroshi Yatsuya, ${ }^{2,4}$ Mohammad Abdullah Al-Mamun, ${ }^{3}$ Abubakr Ahmed Abdullah Al-Shoaibi, ${ }^{2}$ Yoshihisa Hirakawa, ${ }^{2}$ Bilqis Amin Hoque, ${ }^{5}$ Syed Shariful Islam, ${ }^{1}$ Akiko Matsuyama, ${ }^{2,6}$ Hiroyasu Iso, ${ }^{7}$ Atsuko Aoyama ${ }^{2}$

To cite: Khalequzzaman $M$, Chiang C, Choudhury SR, et al. Prevalence of noncommunicable disease risk factors among poor shantytown residents in Dhaka, Bangladesh: a community-based crosssectional survey. BMJ Open 2017;7:e014710. doi:10.1136/ bmjopen-2016-014710

- Prepublication history and additional material for this paper are available online. To view these files please visit the journal (http://dx.doi.org/10. 1136/bmjopen-2016-014710).

Received 12 0ctober 2016 Revised 5 July 2017 Accepted 3 August 2017

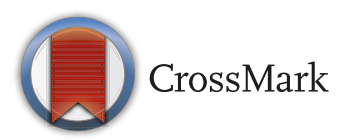

For numbered affiliations see end of article.

Correspondence to

Dr Atsuko Aoyama;

atsukoa@med.nagoya-u.ac.jp

\section{ABSTRACT}

Objectives This study aims to describe the prevalence of non-communicable disease (NCD) risk factors among the urban poor in Bangladesh.

Design We conducted a community-based crosssectional epidemiological study.

Setting The study was conducted in a shantytown in the city of Dhaka. There were 8604 households with 34170 residents in the community. Those households were categorised into two wealth strata based on the housing structure.

Participants The study targeted residents aged 18-64 years. A total of 2986 eligible households with one eligible individual were selected by simple random sampling stratified by household wealth status. A total of 2551 residents completed the questionnaire survey, and 2009 participated in the subsequent physical and biochemical measurements.

Outcome measures A modified WHO survey instrument was used for assessing behavioural risk factors and physical and biochemical measurements, including glycated haemoglobin $(\mathrm{HbA} 1 \mathrm{c})$. The prevalence of NCD risk factors, such as tobacco use, fruit and vegetable intake, overweight/obesity, hypertension, diabetes ( $\mathrm{HbA} 1 \mathrm{C} \geq 6.5 \%$ ) and dyslipidaemia, was described according to household wealth status and gender differences.

Results The prevalence of current tobacco use was $60.4 \%$ in men and $23.5 \%$ in women. Most of them $(90.8 \%)$ consumed more than 1 serving of fruits and vegetables per day; however, only $2.1 \%$ consumed more than 5 servings. Overweight/obesity was more common in women $(39.2 \%)$ than in men $(18.9 \%)$, while underweight was more common in men $(21.0 \%)$ than in women $(7.1 \%)$. The prevalence of hypertension was $18.6 \%$ in men and $20.7 \%$ in women. The prevalence of diabetes was $15.6 \%$ in men and $22.5 \%$ in women, which was much higher than the estimated national prevalence $(7 \%)$. The prevalence of raised total cholesterol ( $\geq 190 \mathrm{mg} / \mathrm{dL}$ ) was $25.7 \%$ in men and $34.0 \%$ in women.

Conclusion The study identified that tobacco use, both overweight and underweight, diabetes, hypertension and

\section{Strengths and limitations of this study}

- This study is the first population-based survey that includes the measurement of glycated haemoglobin (HbA1C) and blood lipid profiles in an urban setting of Bangladesh.

- This study targeted the urban poor, an underserved high-risk population, using representative sampling methods.

- By analysing blood samples using high-performance automatic equipment in a reliable clinical laboratory rather than using portable devices often used for the WHO STEPwise approach to surveillance (STEPS) surveys, we were able to measure low levels of glucose and total cholesterol, as well as highdensity lipoprotein (HDL) and low-density lipoprotein (LDL) cholesterol, triglycerides, HbA1c and complete blood count.

- This study targeted only one urban poor community, which may not represent the nationwide situation.

- We could not measure fasting blood samples, but we used $\mathrm{HbA} 1 \mathrm{C}$ as a viable alternative.

dyslipidaemia were prevalent among the urban poor in Bangladesh.

\section{INTRODUCTION}

Non-communicable diseases (NCDs) are globally recognised threats; thus, reducing the burden of NCDs has been included as one of the targets of the Sustainable Development Goals. ${ }^{1}$ NCDs are new priorities and additional burdens on health in low and middle income countries, where urbanisation and lifestyle changes are advancing rapidly. In addition, low birth weight and childhood malnutrition among the poor may increase 
the risks of cardiovascular diseases and diabetes in adulthood. ${ }^{23}$

Bangladesh is a lower middle income country in South Asia with a population of over 160 million in $2015 .{ }^{4}$ While infectious diseases are still prevalent, the burden of NCDs is also increasing, even among the poor. ${ }^{5}$ Population-based NCD risk factor surveys using a standardised method from the WHO called the STEPwise approach to surveillance (STEPS) ${ }^{6}$ had been conducted four times in the past in Bangladesh. ${ }^{7-11}$ The WHO STEPS approach is a simple, standardised and flexible method that any country can implement to monitor NCD risk factors. This method also allows for comparison across countries. The STEPS instrument includes the following: Step 1: questionnaire-based assessment of behavioural risk factors, such as tobacco use, alcohol consumption, diet and physical activity; Step 2: physical measurements of weight, height, waist and hip circumferences and blood pressure; and Step 3: biochemical measurements of fasting blood glucose and blood lipids, such as total cholesterol. The STEPS surveys of 2002, 2010 and 2013 implemented only Steps 1 and 2. The 2006 survey also conducted Step 3, with measurement of blood glucose and total cholesterol. The 2013 STEPS reported the prevalence of overweight/obesity as $25.7 \%$ (urban $29 \%$ and rural 23\%), hypertension as $21.4 \%$ (urban $27 \%$ and rural $18 \%$ ) and tobacco use as $43.9 \%$ (urban $45 \%$ and rural $43 \%$ ). ${ }^{9}$ The 2006 STEPS reported the prevalence of diabetes as $5.5 \%$ and the prevalence of raised total cholesterol as $6.9 \% .{ }^{10}$ Another population-based survey on blood lipid profile, including high-density lipoprotein (HDL) cholesterol, low-density lipoprotein (LDL) cholesterol and triglycerides, was conducted in 2001, targeting fewer than 500 rural residents. ${ }^{12}$

The urban population is rapidly increasing, as indicated by $3.4 \%$ annual urban population growth in comparison to $1.2 \%$ in the whole nation. ${ }^{4}$ Along with the population growth of the urban poor, the burden of NCDs is increasing due to lifestyle changes and possible childhood undernutrition. However, the situation surrounding NCDs and their risk factors among the urban poor is largely unknown, and very little data on the prevalence of NCD risk factors are available.

We conducted a cross-sectional epidemiological study on NCD risk factors by applying a modified WHO STEPS procedure and a qualitative study on perceptions and attitudes towards NCD risk factors, targeting residents in an urban poor community in Bangladesh. This paper aims to describe the prevalence of NCD risk factors among the urban poor in Dhaka, Bangladesh.

\section{METHODS}

\section{Study site and study population}

We conducted the study in Bauniabadh, an urban poor community in Dhaka, Bangladesh. ${ }^{13}$ The community was originally established by the government in 1972 as a settlement for the poor. An equal-size land plot was allocated to each household at an affordable price. Since then, many residents have moved in or out without registration, and the community expanded with sprawling shantytowns outside the original boundary. Although the original residents were equally poor, some of the current residents have become relatively well off by buying up several plots to build brick houses, while others have remained very poor, sharing shanties made of bamboo and tin.

We defined the target population of this study as adults between 18 and 64 years of age who lived within the original boundary of Bauniabadh. Since accurate census data were not available, we conducted a census-like baseline survey targeting all households within the original boundary between August and November 2014. Individuals or family members who made common provision of food and resided under the same roof were regarded as members of the same household. We identified 8604 households with 34170 residents, among whom 21050 were adults between 18 and 64 years of age. The details of the household survey were described elsewhere. ${ }^{14}$

While all dwellers of the shantytown were recognised as the urban poor, the findings of the baseline survey indicated that household wealth status somewhat varied among the dwellers. We categorised household wealth status into two groups: 'housing level 1' households were defined as those living in single or multi storied houses with concrete roofs, concrete floors and brick walls; 'housing level 2' households were defined as those living in houses with tin roofs, mud or wooden floors, and brick, thatch or bamboo walls. Housing level 1 households usually had their own kitchens and toilets, while several housing level 2 households shared a kitchen and a toilet. The baseline survey data showed that $39 \%$ of the population in the community belonged to the housing level 1 group, while $61 \%$ belonged to the housing level 2 group. There was no gender difference between the two groups.

\section{Sampling}

We applied a simple random sampling procedure stratified according to gender and household wealth status. Target sample size was calculated using the mean and SD of body mass index (BMI) (20.9 and 4.2, respectively, in men) from the 2010 STEPS survey. ${ }^{11}$ We set the difference in the mean BMI between housing level groups to be 1.0 and type I and II errors to be 0.05 and 0.2 , respectively. Although the necessary sample size was calculated to be approximately 300 , we decided to sample 500 individuals in each housing level and gender stratum to obtain enough statistical power (at least 2000 subjects in total). Since only one person was sampled from each household, we randomly selected 1000 households for men and 1000 households for women in each housing level group at the outset of the study. In total, 4000 households were selected, given the possibility that an eligible person may be unavailable in the assigned household or decline participation, as suggested by the STEPS survey guideline $\left(80 \%\right.$ response rate) ${ }^{6}$ We recruited one adult aged 18-64 years from each selected household using the Kish 
grid $^{15}$ until the total number of recruited subjects in each stratum surpassed 500. Pregnant women were excluded. We visited 3560 out of 4000 selected households as the number of individuals with complete data reached 2000. Specifically, among the 3560 selected households, 576 households were found ineligible due to the absence of any eligible persons. Out of 2986 eligible households with one eligible person, 435 selected individuals declined or were unavailable. Finally, 2551 subjects completed an interview conducted in their home (interview response rate: $85.4 \%$ ), and 2009 subjects came to a study clinic in the National Heart Foundation Hospital and Research Institute to complete physical and biochemical measurements (response rate: $67.3 \%$ ).

\section{Staff training and community mobilisation}

Four men and two women who had obtained a college degree and had experience conducting field research were recruited as interviewers and trained on interview skills for five days. Two supervisors managed field activities and monitored data quality. Nurses and laboratory technicians of the National Heart Foundation Hospital and Research Institute were trained to conduct standard physical measurements following WHO guidelines.

To encourage people to participate in the survey, meetings with community leaders and other representatives were held in the community several times before and during the survey period. Community leaders were actively involved in motivating people to participate. Community women who worked as surveyors for our previous baseline study were assigned as community mobilisers. They provided counselling for the selected individuals.

\section{Data collection}

The field epidemiological study was conducted from October 2015 to April 2016, mostly following the standard WHO STEPS procedures. ${ }^{6}$ We used a modified questionnaire from the 2010 Bangladesh STEPS, ${ }^{8}$ which consisted of all core questions and some expanded questions in the WHO prototype, as well as additional questions such as types of tobacco used. We also incorporated the findings of qualitative studies conducted between November 2014 and August $2015^{16}$ and added several questions, such as those related to salt intake. The questionnaire was pretested in adjacent shantytowns and revised several times until all interviewers became confident in completing the interviews.

The interviewers visited the selected household and interviewed the eligible person in the Bengali language. Participants who completed the interview were invited to the study clinic in the National Heart Foundation Hospital and Research Institute for physical measurements and blood sampling. The institute was close to the community, and the cost of transport was provided to participants when they arrived. Those who failed to appear were reminded and motivated by the community mobilisers.
Participants were asked about their medical histories and medications. Afterwards, their height, weight, waist and hip circumferences and blood pressure were measured. Female nurses conducted the anthropometric measurements of female participants. The anthropometric measurements were taken in light clothing without shoes or other heavy accessories. After resting for $15 \mathrm{~min}$, blood pressure was measured three times in the right upper arm by using an automatic digital sphygmomanometer (HEM-8712, Omron, Kyoto, Japan). Systolic blood pressure (SBP), diastolic blood pressure (DBP) and pulse per minute were recorded, and the arithmetic mean of the second and third readings of blood pressure was used for the analysis. In cases of arrhythmia, blood pressure was measured twice using a manual sphygmomanometer.

The poor study participants, who worked very early in the morning, could come to the study clinic only in the afternoon. Thus, random blood samples were taken to measure glucose; glycated haemoglobin (HbAlc); total, HDL and LDL cholesterol; triglycerides; and complete blood count. Approximately $10 \mathrm{~mL}$ of venous blood was drawn and analysed at the clinical laboratory of the National Heart Foundation Hospital and Research Institute using calibrated automatic analysers (Dimension RxL Max, Siemens, Washington DC, USA, for glucose, total, HDL and LDL cholesterol, triglycerides and HbAlc; and Hematology Analyzer Mythic 22, Orphée, Geneva, Switzerland, for haemoglobin, red blood cell, white blood cell and platelet counts).

\section{Data analysis}

The participants' names were separated from the original sheets, which were coded with serial numbers. The anonymised data were entered into a programmed data entry template, and the accuracy of the data entry was verified using a $10 \%$ double-entry method. There were no missing variables in the present analyses except for one person's gender. We excluded this subject from the data analysis.

We categorised all continuous readings of physical and biochemical measurements according to well-defined standards (with some modification). BMI was calculated as weight in kilograms divided by height in metres squared and then categorised into four groups: <18.5, 18.5-24.9, 25-29.9 and $\geq 30 \mathrm{~kg} / \mathrm{m}^{2}{ }^{2}{ }^{7}$ Hypertension was defined as SBP $\geq 140 \mathrm{mmHg}$, DBP $\geq 90 \mathrm{mmHg}$ or the use of any antihypertensive medication. ${ }^{18}$ Random blood glucose levels were classified as follows: $<140,140-199$ and $\geq 200 \mathrm{mg} / \mathrm{dL}$. HbA1c levels were classified as follows: $<5.7,5.7-6.4$ and $\geq 6.5 \% .{ }^{19}$ Blood lipid levels were classified by the following cut-off values: total cholesterol levels as $<150,150-189$, 190-199, 200-239 and $\geq 240 \mathrm{mg} / \mathrm{dL}$; HDL cholesterol levels as $<40,40-49$ and $\geq 50 \mathrm{mg} / \mathrm{dL}$; LDL cholesterol levels as <100, 100-129, $130-159$ and $\geq 160 \mathrm{mg} / \mathrm{dL}$; and triglyceride levels as $<100,100-149,150-199$ and $\geq 200 \mathrm{mg} / \mathrm{dL} .{ }^{20}{ }^{21}$ (The meaning of each category of the indicators are shown in online supplementary note).

Analyses adjusted for the complex survey design with four strata by the housing level and gender were 
conducted. To deal with unequal probabilities of selection, we presented sampling weight corrected prevalence or means for total men and women. Since the survey was done in a single community, the finite population correction was applied to the calculation of unbiased $95 \%$ CIs. For variables with skewed distributions, log-transformed data were used. To test the differences between men and women for each categorical data variable, the $\chi^{2}$ test was applied. Student's t-test was used for testing mean differences between genders. All statistical analyses were performed using the statistical software Stata IC, Release 12.

\section{Ethical considerations}

This study was approved by the Bioethics Review Committee of Nagoya University School of Medicine, Japan (approval no. 2014-0021). The institutional review boards of Bangabandhu Sheikh Mujib Medical University and National Heart Foundation Hospital and Research Institute, Bangladesh, also approved the study. Written informed consent was obtained from all participants. Participants with no education provided fingerprints on the consent sheets after receiving sufficient verbal explanation.

\section{RESULTS}

In total, 2551 eligible persons participated in the questionnaire-based interview: 1289 (674 men and 615 women) were from the housing level 1 group, and 1262 (684 men and 578 women) were from the housing level 2 group. Among the interview participants, 2009 individuals $(78.8 \%)$ participated in the physical and biochemical measurements, with 1002 (504 men and 498 women) from the housing level 1 group and 1007 (504 men and 503 women) from the housing level 2 group.

Table 1 shows the demographic and behavioural characteristics of the sample. The mean age of the 2551 participants was 35.8 years for men and 35.6 years for women. Current tobacco users were $60.4 \%$ of men $(54.6 \%$ in housing level 1 and $64.2 \%$ in housing level 2) and 23.5\% of women (14.8\% in housing level 1 and $29.1 \%$ in housing level 2). Tobacco smoking (cigarette, beedi, and so on) was reported only by men $(53.0 \%$ in total, $48.7 \%$ in housing level 1 and $55.8 \%$ in housing level 2). Smokeless tobacco chewing was more common among women $(23.5 \%$ in total, $14.8 \%$ in housing level 1 and $29.1 \%$ in housing level 2) than men $(16.3 \%$ in total, $11.6 \%$ in housing level 1 and $19.3 \%$ in housing level 2). Alcohol use was reported only by men (3.2\% in total, $4.6 \%$ in housing level 1 and $2.3 \%$ in housing level 2).

Most of the participants $(92.9 \%$ of men and $88.7 \%$ of women) consumed at least 1 serving of fruits and vegetables per day; however, only $0.9 \%$ of men and $3.3 \%$ of women consumed more than 5 servings. Among those who had less than 1 serving were $7.1 \%$ of men $(7.3 \%$ in housing level 1 and $6.9 \%$ in housing level 2) and $11.3 \%$ of women (3.3\% in housing level 1 and $16.5 \%$ in housing level 2). Only $20.9 \%$ of men and $21.0 \%$ of women reported that they never added table salt to their meals, while $55.9 \%$ of men and $51.2 \%$ of women always added salt. The prevalence of moderate or high levels of total physical activity ( $\geq 600$ MET minutes per week) was $76.5 \%$ in men and $35.8 \%$ in women, which is comparable with the findings for the urban population of the 2010 STEPS. ${ }^{22}$

Comparing with the housing level 1 group, the housing level 2 group participants were less likely to be educated, be employed, eat fruits and vegetables and add salt. They were more likely to be day labourers, tobacco users and physically active individuals $(\mathrm{p}<0.05$ for all, not shown in the tables).

Table 2 shows the percentages of biological indicators classified by appropriate criteria, and table 3 shows the prevalence of biological NCD risk factors by gender and household wealth status. Overweight/obesity was more common in women $(39.2 \%)$ than men $(18.9 \%)$, while underweight was more common in men $(21.0 \%)$ than women $(7.1 \%)$. Overweight/obesity prevalence was higher than the estimated national prevalence for men $(16.4 \%)$ and women $(24.2 \%){ }^{23}$

According to WHO-recommended cut-off points, ${ }^{24}$ the prevalence of increased waist circumference (men $>94 \mathrm{~cm}$; women $>80 \mathrm{~cm})$ and increased waist-hip ratio (men $\geq 0.90$; women $\geq 0.85$ ) were $9.2 \%$ and $64.4 \%$ in men and $53.3 \%$ and $80.1 \%$ in women, respectively. The prevalence of increased waist circumference in men was $16.2 \%$ according to the cut-off point for South Asian men $(>90 \mathrm{~cm})$ recommended by the International Diabetes Federation. $^{24}$

The prevalence of hypertension was $18.6 \%$ in men and $20.7 \%$ in women, which was comparable with the findings of previous STEPS surveys. ${ }^{9-11}$

The prevalence of diabetes $(\mathrm{HbA} 1 \mathrm{c} \geq 6.5 \%$, random blood glucose $\geq 200 \mathrm{mg} / \mathrm{dL}$ or diabetes treatment ${ }^{19}$ was $15.6 \%$ in men $(13.7 \%$ in housing level 1 and $16.9 \%$ in housing level 2) and $22.5 \%$ in women (20.7\% in housing level 1 and 23.7\% in housing level 2), which was much higher than the national prevalence estimated by the WHO (men $8.6 \%$; women $7.4 \%$ ). ${ }^{23}$ Only $4.5 \%$ of men and $5.4 \%$ of women showed diabetic levels of random blood glucose, indicating the unreliability of random blood glucose in screening for diabetes.

The mean value of total cholesterol was $167 \mathrm{mg} / \mathrm{dL}$ in men and $174 \mathrm{mg} / \mathrm{dL}$ in women, and the mean value of HDL cholesterol was as low as $33 \mathrm{mg} / \mathrm{dL}$ in men and $38 \mathrm{mg} / \mathrm{dL}$ in women. The prevalence of raised total cholesterol $(\geq 190 \mathrm{mg} / \mathrm{dL}$ or on medication) was $25.7 \%$ in men and $34.0 \%$ in women. The high-risk range of low level HDL cholesterol $(<40 \mathrm{mg} / \mathrm{dL})^{20}$ was $73.2 \%$ in men and $55.7 \%$ in women, and the high-risk range of borderline-high to high level LDL cholesterol $(\geq 130 \mathrm{mg} /$ dL) ${ }^{20}$ was $11.7 \%$ in men and $12.6 \%$ in women. High level triglycerides $(\geq 200 \mathrm{mg} / \mathrm{dL})^{20}$ were more common in men $(32.2 \%)$ than women $(22.4 \%)$.

Regarding the prevalence of physical and biochemical risk factors, such as overweight/obesity, hypertension, 


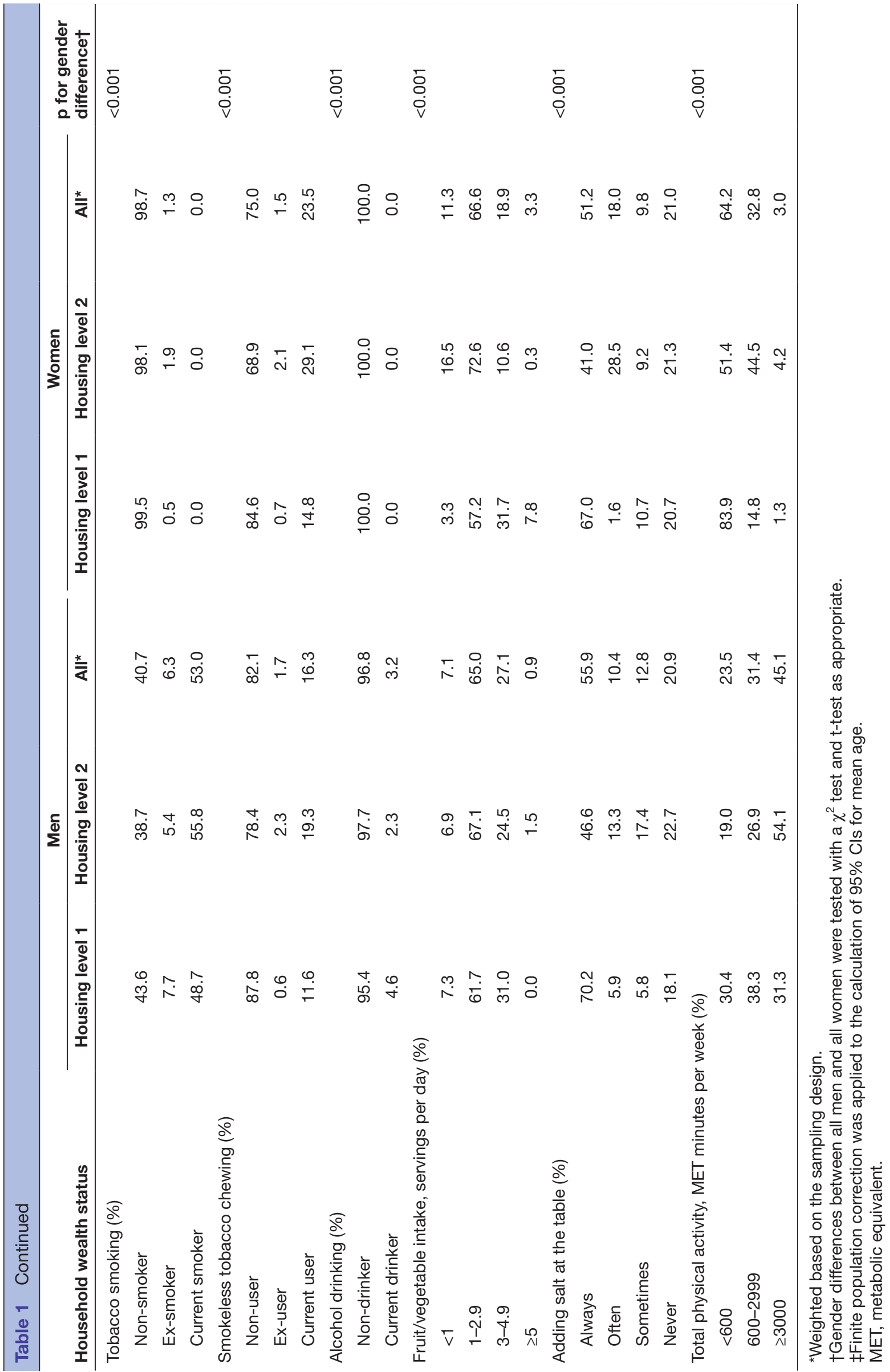

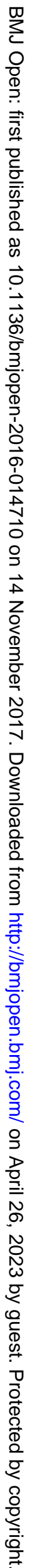




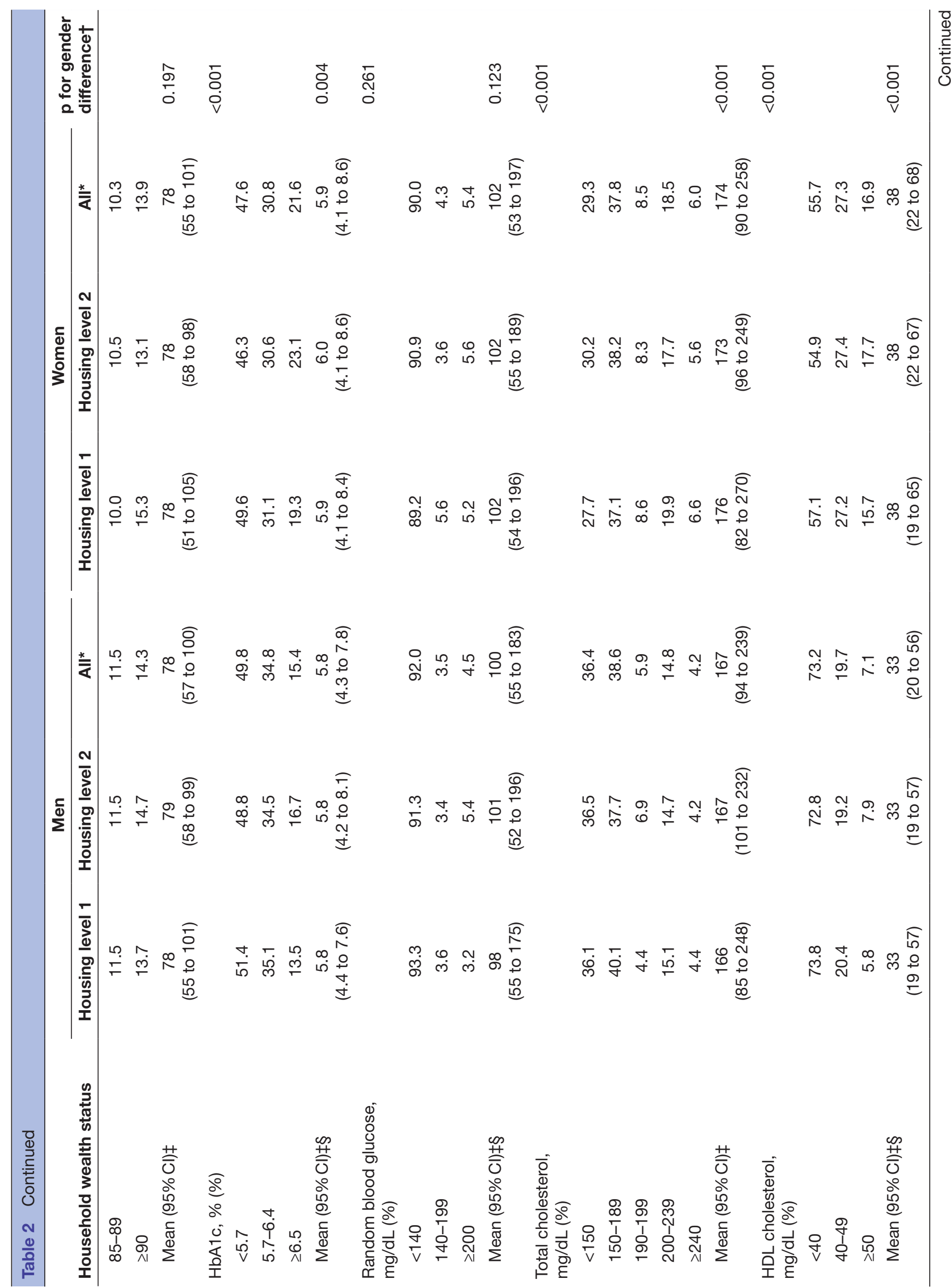




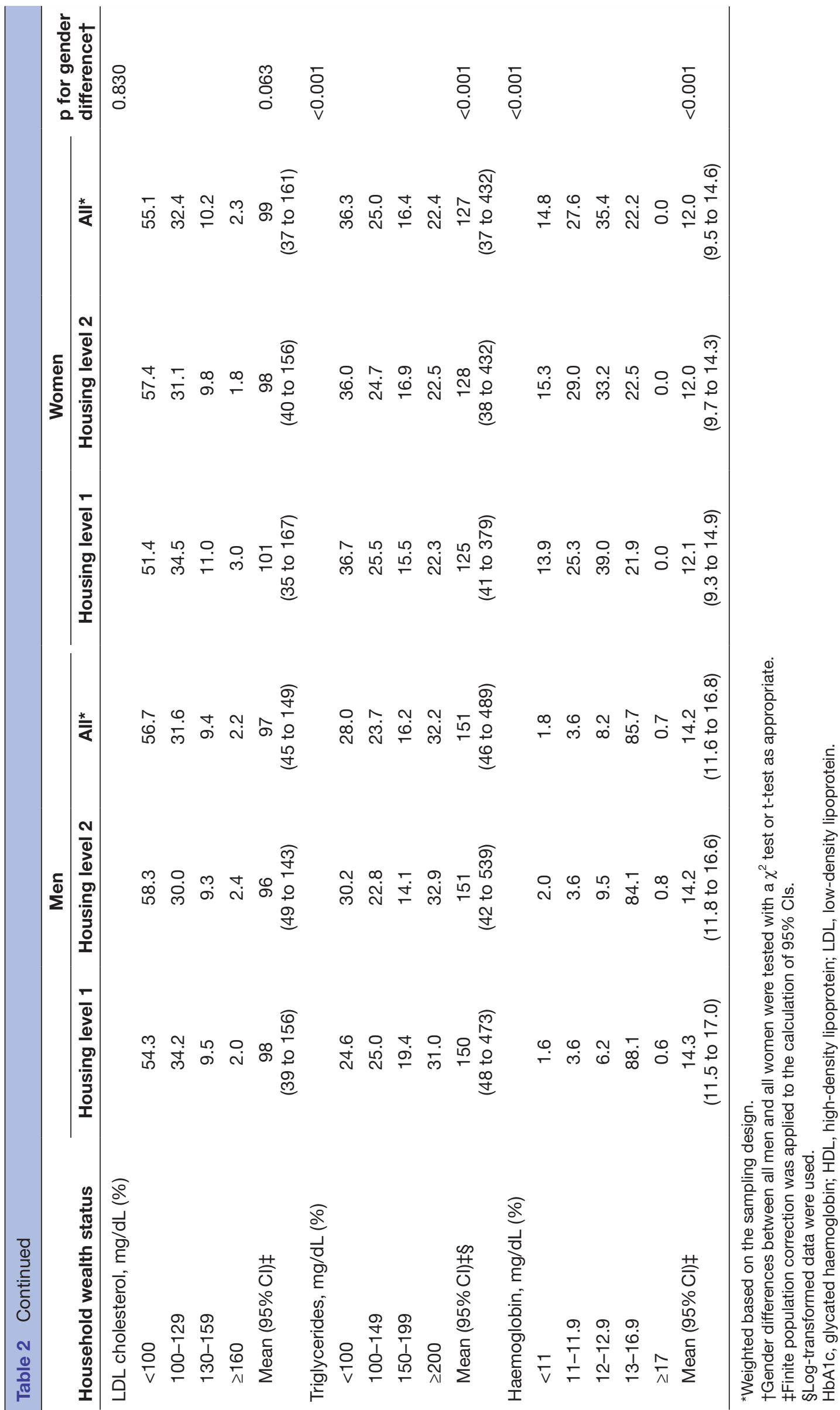




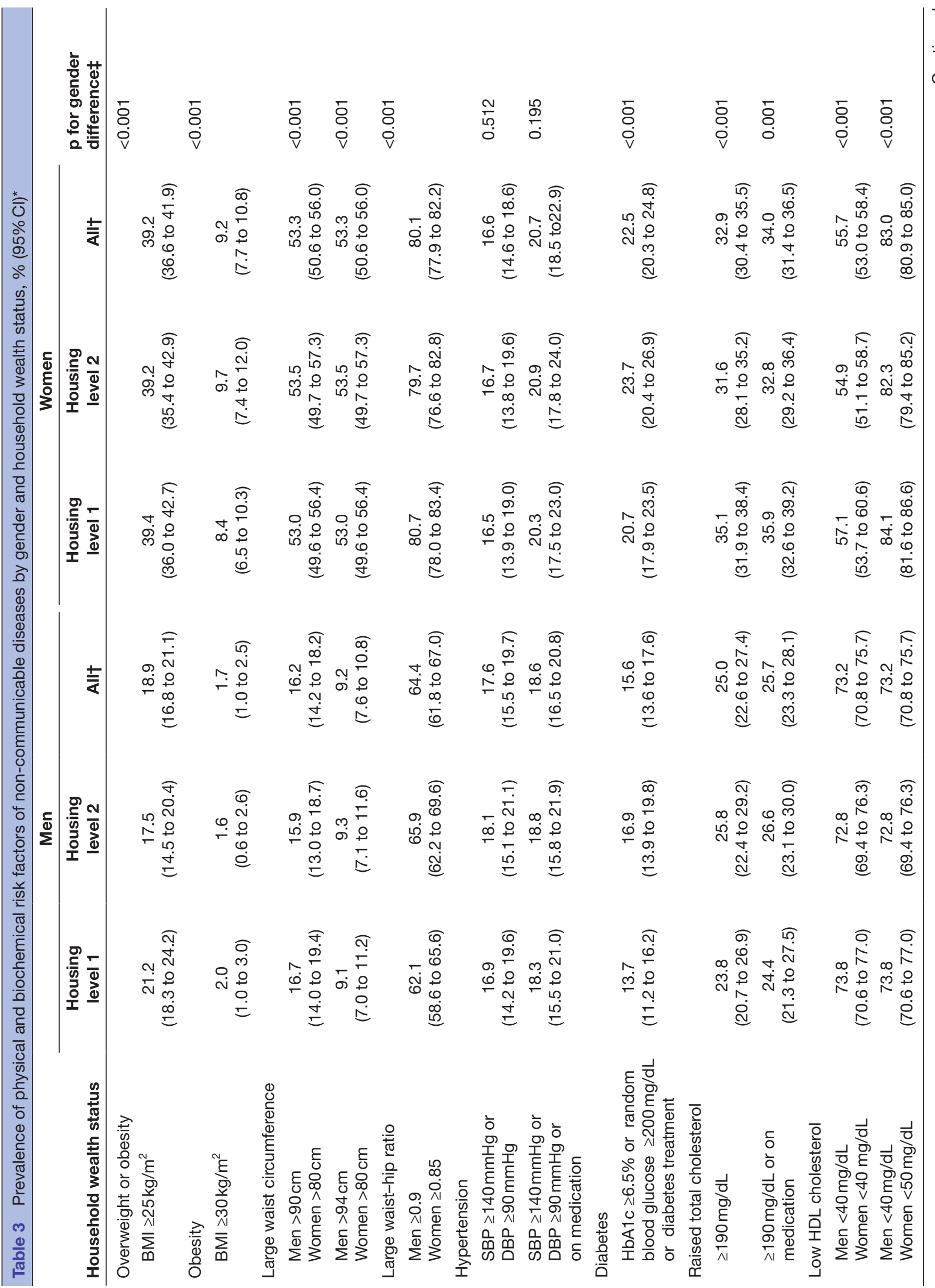


diabetes and dyslipidaemia, a significant difference was not found between the housing level 1 and level 2 groups (not shown in tables).

\section{DISCUSSION}

This study is the first comprehensive epidemiological survey of various NCD risk factors, including HbAlc, among the urban poor in Bangladesh, who are considered to be an underserved high-risk population.

We found that the overweight/obesity prevalence of both men and women was higher than the estimated national prevalence. The overweight/obesity prevalence in women was as high as $39.2 \%$, which could be attributed to the sedentary lifestyle of urban women. ${ }^{25}$ Overweight/ obesity and underweight were equally prevalent in men, reflecting their socioeconomic situation: many men still had to be involved in hard physical labour, ${ }^{26}$ while some men could afford to eat well. Our findings suggested that both overweight/obesity and underweight should be addressed simultaneously.

The high prevalence of an increased waist-hip ratio in both men and women and increased waist circumference in women indicated high risks of metabolic syndrome among the urban poor. However, further studies are needed to identify appropriate cut-off points and clinical implications of BMI, waist circumference and waist-hip ratio in Bangladesh, considering the discrepancy between waist circumference and waist-hip ratio in men.

The prevalence of diabetes in both housing levels and in both genders was much higher than the WHO-estimated national prevalence ${ }^{23}$ and the prevalence findings from the 2006 STEPS survey (men $7.6 \%$; women $2.8 \%) .{ }^{10}$ The findings of our study were in line with the trend of increasing prevalence reported elsewhere ${ }^{23}$; therefore, diabetes prevalence may have increased since the most recent surveys. Diabetes prevalence among the poor may be higher than the national average, indicating an association between low socio-economic status and increased diabetes prevalence, as shown in studies conducted in high income countries. ${ }^{27} 28$ The higher diabetes prevalence among the urban poor may be attributed to childhood undernutrition, but further investigation is needed.

Diabetes prevalence was higher in women than men, contrary to the findings of the 2006 survey. The urban poor women may be more prone to diabetes than men, since gender differences in diabetes prevalence may vary depending on socio-economic situations. ${ }^{29}$ However, the higher HbAlc levels in women compared with men might have been due to the higher prevalence of anaemia (haemoglobin $<11 \mathrm{mg} / \mathrm{dL})^{30}$ in women $(14.8 \%)$ than men $(1.8 \%)$, which was reported to shift HbAlc values towards the higher end. ${ }^{31-34}$ In our study, we used the WHO-recommended HbA1c cut-off point, ${ }^{35}$ but caution is needed given the high anaemia prevalence. Further studies are needed to fully understand and interpret HbAlc values in low and lower middle income countries. 
Our study is the first population-based survey of blood lipid profiles of the urban poor in Bangladesh. A highrisk range of low HDL cholesterol was highly prevalent, but desirable ranges of both low total cholesterol and LDL cholesterol were highly prevalent as well. These findings were consistent with the findings of a previous study of a rural population, although a desirable range of low LDL cholesterol was more prevalent in our study than in the previous study. ${ }^{12}$ The clinical implications of low levels of HDL and LDL cholesterol in this population need to be investigated further. The relatively high prevalence of high-level triglycerides might be overestimated, since random blood samples were used.

A high prevalence of tobacco use was confirmed in this study. This finding is consistent with those of previous studies. ${ }^{3637}$ Chewing tobacco products seemed to be culturally tolerated, as evident in the finding that women often chewed tobacco but refrained from smoking tobacco. Different approaches for men and women are needed for tobacco control.

Approximately $80 \%$ of the participants added table salt to their meals, although their meals were already cooked and seasoned with salt. Further studies are needed to determine the amount of salt intake in this population, since we did not measure total salt intake. Our qualitative study found that the community residents sprinkled table salt on rice because they liked the salty taste and served salt with meals for welcoming guests. ${ }^{16}$ While salt reduction is known to be a cost effective strategy to prevent cardiovascular diseases, ${ }^{38} 39$ it is difficult to modify the dietary habits of individuals in a short time period. Thus, a long-term community-wide campaign to modify the diets of community residents is necessary, as shown in successful model programmes in Japan. $^{4041}$

The strength of this study is that we targeted the urban poor, an underserved high-risk population, using representative sampling methods. Through analysing blood samples using high-performance automatic equipment in a reliable clinical laboratory rather than using portable devices often used in STEPS surveys, we were able to measure low levels of glucose and total cholesterol, as well as HDL and LDL cholesterol, triglycerides, HbAlc and complete blood count. However, this study has several limitations. First, we targeted only one urban poor community, which may not represent the nationwide situation. Second, we could not measure fasting blood samples. While random blood glucose values were unreliable in screening for diabetes, we found that measuring HbAlc may be a viable alternative.

In conclusion, the current survey revealed a high prevalence of NCD risk factors among the urban poor in Bangladesh. Diabetes, dyslipidaemia, hypertension, tobacco use and both overweight and underweight were prevalent, indicating the dual burden among the urban poor. Our findings can serve as baseline epidemiological data and help policymakers develop appropriate NCD control strategies.

\section{Author affiliations}

${ }^{1}$ Department of Public Health and Informatics, Bangabandhu Sheikh Mujib Medical University, Dhaka, Bangladesh

${ }^{2}$ Department of Public Health and Health Systems, Nagoya University School of Medicine, Nagoya, Japan

${ }^{3}$ Department of Epidemiology and Research, National Heart Foundation Hospital and Research Institute, Dhaka, Bangladesh

${ }^{4}$ Department of Public Health, Fujita Health University School of Medicine, Toyoake, Aichi, Japan

${ }^{5}$ Environment and Population Research Centre, Dhaka, Bangladesh

${ }^{6}$ Nagasaki University School of Tropical Medicine and Global Health, Nagasaki,

Japan

${ }^{7}$ Public Health Graduate School of Medicine, Osaka University, Suita, Osaka, Japan

Acknowledgements The authors wish to thank the residents in the Bauniabadh community and the staff members of the field survey, the National Heart Foundation Hospital and Research Institute and the Environment and Population Research Centre for their assistance in data collection and for their valuable advice.

Contributors AA, MK, SRC, HY and AM designed the study; MK, SRC, MAA, BAH and SSI conducted the field survey and data collection; CC, MK, HY, SRC and AA statistically analysed and interpreted the data; $\mathrm{AA}, \mathrm{MK}, \mathrm{CC}$ and AAAA drafted the manuscript; and $\mathrm{HY}, \mathrm{SRC}, \mathrm{HI}, \mathrm{SSI}, \mathrm{AM}$ and YH provided critical input on the draft. All authors approved the final draft.

Funding This work was supported by Grants-in-Aid for Scientific Research (KAKENHI) from the Japan Society for the Promotion of Science (A, 25257505 to $A$ ) and in part by the Sciences Research Grant for Research on Global Health Issues from the Japan Agency for Medical Research and Development (16jk0110008h0102 to AA).

\section{Competing interests None declared.}

Ethics approval Bioethics Review Committee of Nagoya University School of Medicine, Japan, and Institutional Review Boards of Bangabandhu Sheikh Mujib Medical University and National Heart Foundation Hospital and Research Institute, Bangladesh.

Provenance and peer review Not commissioned; externally peer reviewed. Data sharing statement No additional data are available.

Open Access This is an Open Access article distributed in accordance with the Creative Commons Attribution Non Commercial (CC BY-NC 4.0) license, which permits others to distribute, remix, adapt, build upon this work non-commercially, and license their derivative works on different terms, provided the original work is properly cited and the use is non-commercial. See: http://creativecommons.org/ licenses/by-nc/4.0/

(c) Article author(s) (or their employer(s) unless otherwise stated in the text of the article) 2017. All rights reserved. No commercial use is permitted unless otherwise expressly granted.

\section{REFERENCES}

1. United Nations. Sustainable development goals. Goal 3: ensure healthy lives and promote well-being for all at all ages. http://www.u n.org/sustainabledevelopment/health (accessed 8 Sep 2016).

2. Risnes KR, Vatten LJ, Baker JL, et al. Birthweight and mortality in adulthood: a systematic review and meta-analysis. Int $\mathrm{J}$ Epidemiol 2011;40:647-61.

3. Whincup PH, Kaye SJ, Owen CG, et al. Birth weight and risk of type 2 diabetes: a systematic review. JAMA 2008;300:2886-97.

4. The World Bank. World development indicators. http://databank. worldbank.org/data/reports.aspx?source=2\&country=BGD (accessed 8 Sep 2016)

5. Khan JAM, Trujillo AJ, Ahmed S, et al. Distribution of chronic disease mortality and deterioration in household socioeconomic status in rural Bangladesh: an analysis over a 24-year period. Int $\mathrm{J}$ Epidemiol 2015;44:1917-26.

6. WHO Chronic Diseases and Health Promotion Program. STEPwise approach to surveillance (STEPS). http://www.who.int/chp/steps/en/ (accessed 8 Sep 2016).

7. Rahman M, Flora MS, Akter SFU, et al. Behavioral risk factors of non-communicable diseases in Bangladesh - tobacco usage. dietary pattern and physical activity status http://www.who.int/chp/steps/ BangladeshSTEPSReport.pdf?ua=1 (accessed 21 Nov 2016). 
8. Bangladesh Society of Medicine, WHO Country Office for Bangladesh, and Ministry of Health and Family Welfare. Noncommunicable disease risk factor survey, Bangladesh 2010. New Delhi: WHO Regional Office for South-East Asia, 2011.

9. Zaman MM, Bhuiyan MR, Karim MN, et al. Clustering of noncommunicable diseases risk factors in Bangladeshi adults: an analysis of STEPS survey 2013. BMC Public Health 2015;15:659.

10. Zaman MM, Choudhury SR, Ahmed J, et al. Blood glucose and cholesterol levels in adult population of Bangladesh: results from STEPS 2006 survey. Indian Heart J 2016;68:52-6.

11. Zaman MM, Rahman MM, Rahman MR, et al. Prevalence of risk factors for non-communicable diseases in Bangladesh: results from STEPS survey 2010. Indian J Public Health 2016;60:17-25.

12. Zaman MM, Choudhury SR, Ahmed J, et al. Plasma lipids in a rural population of Bangladesh. Eur J Cardiovasc Prev Rehabil 2006;13:444-8.

13. Hoque BA, Suzuki K, Sato-Yamamoto $Y$, et al. Water and sanitation in an urban poor settlement: a case study of Bauniabad, Bangladesh. Tokyo: United Nations University Institute for the Advanced Study of Sustainability, 2005

14. Khalequzzaman M, Chiang C, Hoque BA, et al. Population profile and residential environment of an urban poor community in Dhaka, Bangladesh. Environ Health Prev Med 2017;22:1.

15. Kish L. A procedure for objective respondent selection within the household. J Am Stat Assoc 1949;44:380-7.

16. Aoyama A, Matsuyama A, Al-Shoaibi AAA, et al. Non-communicable disease (NCD) risk factors among the urban poor in Bangladesh - preliminary findings of a community based qualitative study. Proceeding of the 26th Annual Conference of Japan Society for International Development. 2015;252-5.

17. WHO Consultation of Obesity. Obesity: preventing and managing the global epidemic: report of a WHO consultation. Geneva: WHO, 2000.

18. Mancia G, Fagard R, Narkiewicz K, et al. ESH/ESC Guidelines for the management of arterial hypertension: The Task Force for the management of arterial hypertension of the European Society of Hypertension (ESH) and of the European Society of Cardiology (ESC). J Hypertens 2013;31:1281-357.

19. American Diabetes Association. Diagnosis and classification of diabetes mellitus. Diabetes Care 2014;37(Suppl 1):S81-90.

20. National Cholesterol Education Program (NCEP) Expert Panel. Third report of the NCEP expert panel on detection, evaluation, and treatment of high blood cholesterol in adults (Adult Treatment Panel III) final report. Circulation 2002;106:3143-421.

21. World Health Organization. Prevalence of raised total cholesterol ( $\geq 190 \mathrm{mg} / \mathrm{dl}$ ). http://apps.who.int/gho/indicatorregistry/App_Main/ view_indicator.aspx?iid=2382 (accessed 9 Feb 2017).

22. Moniruzzaman M, Zaman MM, Islalm MS, et al. Physical activity levels in Bangladeshi adults: results from STEPS survey 2010. Public Health 2016;137:131-8.

23. World Health Organization. Diabetes country profiles 2016 , Bangladesh. http://www.who.int/diabetes/country-profiles/bgd_en. pdf?ua $=1$ (accessed 8 Sep 2016)

24. World Health Organization. Waist circumference and waist-hip ratio: report of a WHO expert consultation, Geneva, 8-11 December 2008. Geneva: WHO. 2011.
25. Sarma H, Saquib N, Hasan MDM, et al. Determinants of overweight or obesity among ever-married adult women in Bangladesh. BMC Obesity 2016;3:13.

26. Ahmed T, Mahfuz M, Islam MM, et al. The MAL-ED cohort study in Mirpur, Bangladesh. Clin Infect Dis 2014;59(Suppl 4):S280-6.

27. Insaf TZ, Strogatz DS, Yucel RM, et al. Associations between race, lifecourse socioeconomic position and prevalence of diabetes among US women and men: results from a population-based panel study. J Epidemiol Community Health 2014;68:318-25.

28. Joshy G, Porter T, Le Lievre C, et al. Prevalence of diabetes in New Zealand general practice: the influence of ethnicity and social deprivation. J Epidemiol Community Health 2009;63:386-90.

29. Hilawe EH, Yatsuya H, Kawaguchi L, et al. Differences by sex in the prevalence of diabetes mellitus, impaired fasting glycaemia and impaired glucose tolerance in sub-Saharan Africa: a systematic review and meta-analysis. Bull World Health Organ 2013:91:671-82.

30. WHO Vitamin and Mineral Nutrition Information System. Haemoglobin concentrations for the diagnosis of anaemia and assessment of severity. Geneva: WHO, 2011.

31. English E, Idris I, Smith G, et al. The effect of anaemia and abnormalities of erythrocyte indices on $\mathrm{HbA} 1 \mathrm{c}$ analysis: a systematic review. Diabetologia 2015;58:1409-21.

32. Hardikar PS, Joshi SM, Bhat DS, et al. Spuriously high prevalence of prediabetes diagnosed by $\mathrm{HbA} 1 \mathrm{c}$ in young Indians partly explained by hematological factors and iron deficiency anemia. Diabetes Care 2012;35:797-802.

33. Hong JW, Ku CR, Noh JH, et al. Association between the presence of iron deficiency anemia and hemoglobin A1c in Korean adults: the 2011-2012 Korea national health and nutrition examination survey. Medicine 2015;94:e825

34. Simmons D, Hlaing T. Interpretation of HbA1c: Association with mean cell volume and haemoglobin concentration. Diabet Med 2014;31:1387-92.

35. World Health Organization. Use of glycated haemoglobin (HbA1c) in the diagnosis of diabetes mellitus: abbreviated report of a WHO consultation. Geneva: WHO, 2010.

36. Nargis N, Thompson ME, Fong GT, et al. Prevalence and patterns of tobacco use in Bangladesh from 2009 to 2012: evidence from international tobacco control (ITC) study. PLoS One 2015;10:e0141135

37. Pallipudi KM, Sinha DN, Choudhury S, et al. Predictors of tobacco smoking and smokeless tobacco use among adults in Bangladesh. Indian J Cancer 2012;49:387-92.

38. Sutton L, Karan A, Mahal A. Evidence for cost-effectiveness of lifestyle primary preventions for cardiovascular disease in the AsiaPacific Region: a systematic review. Global Health 2014;10:79.

39. World Health Organization. The SHAKE technical package for salt reduction. Geneva: WHO, 2016.

40. Iso $\mathrm{H}$, Shimamoto $\mathrm{T}$, Naito $\mathrm{Y}$, et al. Effects of a long-term hypertension control program on stroke incidence and prevalence in a rural community in northeastern Japan. Stroke 1998;29:1510-8.

41. Nakagawa H, Miura K. Salt reduction in a population for the prevention of hypertension. Environ Health Prev Med 2004;9:123-9. 